\title{
OUTLOOK
}

\section{Mixed knobs in corn cobs}

\author{
Piero Lamelza and Michael A. Lampson \\ Department of Biology, School of Arts and Sciences, University of Pennsylvania, Philadelphia, Pennsylvania 19104, USA
}

Maize heterochromatic knobs cheat female meiosis by forming neocentromeres that bias their segregation into the future egg cell. In this issue of Genes \& Development, Swentowsky and colleagues (pp. 1239-1251) show that two types of knobs, those composed of $180-b p$ and TR1 sequences, recruit their own novel and divergent kinesin-14 family members to form neocentromeres.

During male meiosis, all four of the meiotic products eventually develop into functional sperm. In contrast, only one of the four meiotic products of female meiosis will develop into an egg. Homologous chromosomes normally segregate randomly during meiotic divisions, and therefore each has a $50 \%$ chance of being inherited by the future egg cell. However, there are genetic elements that modify meiotic chromosome segregation to increase their chances of being segregated into the egg at the expense of their homolog (Akera et al. 2019). "Meiotic drive" refers to when a gene manipulates meiosis to increase its transmission (Burt and Trivers 2006).

The knobs in maize were the first female meiotic drivers to be discovered (Rhoades 1942). Knobs are heterochromatic regions located near the center or ends of chromosome arms. The DNA within knobs is composed of two types of tandem repeats: the 180-bp repeat and the TR1 repeat. A variant of maize chromosome 10 containing both TR1 and 180-bp knobs (Ab10) exhibits strong female meiotic drive when in a heterozygous state with a normal chromosome 10 , with $\sim 75 \%$ of progeny inheriting Ab10 knobs (Rhoades 1942; Kanizay et al. 2013).

The meiotic drive of knobs can be explained by their "neocentromere" activity during meiosis (Fig. 1A). Knobs use microtubules to move toward poles of the meiotic spindle during anaphase I and II, arriving at spindle poles quicker than centromeres and drastically stretching chromosome arms. If one recombination event occurs between knob and centromere, then each homolog on either side of the meiotic bivalent will possess a knob. At anaphase I, each knob leads its chromosome to the opposite spindle pole. At anaphase II, the knobs lead their

[Keywords: meiotic drive; anaphase; chromosome segregation; heterochromatin; kinesin-14; knob; meiosis; neocentromere; tandem repeat]

Corresponding author: lampson@sas.upenn.edu

Article is online at http://www.genesdev.org/cgi/doi/10.1101/gad.343350. 120 . chromosome to the most exterior meiotic products, presumably due to their already close proximity to the exterior spindle poles. This biased segregation of knobs into the most terminal meiotic products works to their advantage because only the basal meiotic product of female meiosis will develop into the egg.

Although the model outlined above was proposed by Marcus Rhoades in the 1950s (Rhoades 1952), it was only recently discovered how knobs move along spindle microtubules. There were already hints that knob movement functionally differed from centromeres. For example, knobs do not form kinetochores (Kelly Dawe et al. 1999), which form on centromeres and directly bind microtubules. A recent study by Dawe et al. (2018) found that a divergent kinesin-14 family member, Kindr, specifically binds to 180 -bp repeat-containing knobs and is required for both their neocentromere activity and meiotic drive. Kinesin-14 family members are minus end-directed microtubule motors with roles in spindle assembly and organization (She and Yang 2017). In vitro analysis revealed that KINDR is also a minus end-directed motor, strongly suggesting that KINDR binds and pulls 180-bp knobs toward spindle poles by directly walking on microtubules.

Until now it was unknown how TR1 knobs bind and move along microtubules. In this issue of Genes \& Development, Swentowsky et al. (2020) analyzed a higher-quality maize genome assembly and found a new kinesin-14 family member (Trkin). Trkin is quite divergent from other known kinesin-14 family members, including Kindr, and only shares significant homology in the motor domain. Unlike Kindr and other kinesin-14 members, Trkin has a nuclear localization signal. Despite being drastically divergent, TRKIN is also a functional minus end motor, as shown by in vitro microtubule gliding assays. The investigators also used immunofluorescence to show that TRKIN localizes specifically to TR1 neocentromeres during meiosis. Finally, the investigators found an association between full-length Trkin expression and TR1 neocentromere activity in natural Ab10 variants, suggesting that TRKIN is required for TR 1 neocentromere formation. Taken together, the data support a model in

\footnotetext{
(C) 2020 Lamelza and Lampson This article is distributed exclusively by Cold Spring Harbor Laboratory Press for the first six months after the full-issue publication date (see http://genesdev.cshlp.org/site/misc/ terms.xhtml). After six months, it is available under a Creative Commons License (Attribution-NonCommercial 4.0 International), as described at http://creativecommons.org/licenses/by-nc/4.0/.
} 
A

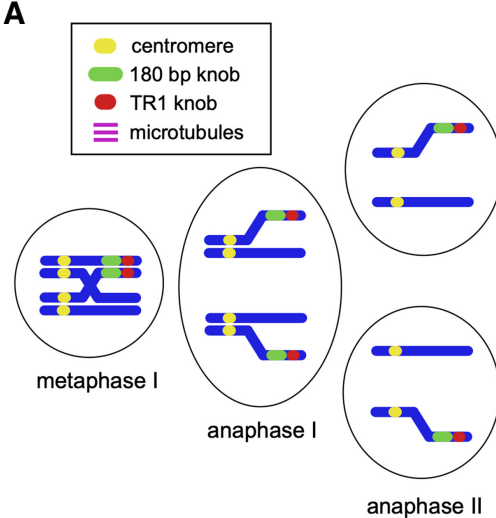

anaphase II

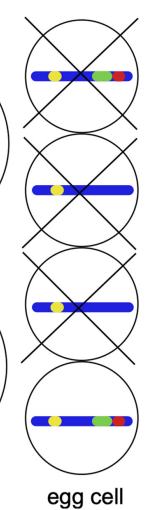

B
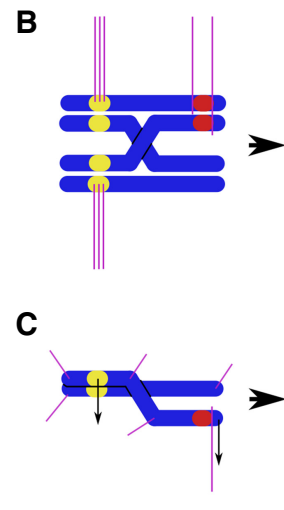

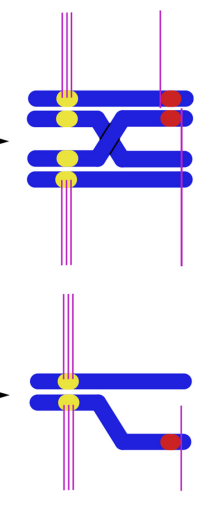

Figure 1. (A) The Rhoades model of meiotic drive. Individuals heterozygous for knobs undergo one recombination event between knobs and centromeres, resulting in one chromatid on each side of the bivalent containing a knob. At anaphase I, knobs move quickly along the meiotic spindle and lead the rest of the chromosome toward spindle poles. In meiosis II, the close proximity of knobs to the terminal spindle poles allows them to segregate preferentially toward the terminal meiotic products (shown at top and bottom). Only the bottom meiotic product develops into the egg cell. $(B)$ Hypothetical directional switching mediated by TR1 neocentromeres. Because knobs will be held together by sister chromatid cohesion at metaphase I, they likely will bind microtubules from the same spindle pole. TR 1 neocentromeres may play a role in switching which microtubules knobs bind to in order to resolve directional conflicts between knobs and centromeres. $(C)$ Hypothetical centromere reorientation mediated by TR1 neocentromeres. Although a knob is close to the terminal spindle pole in meiosis II, its linked centromere is not necessarily oriented toward the same pole. Because TRKIN is present on TR 1 knobs during prophase II, TR 1 neocentromeres may use the nascent meiotic spindle that is forming around chromosomes to apply tension to their chromatids (arrow from TR1 knob), thereby orienting their linked centromere toward the sample spindle pole (arrow from centromere). This could occur before the meiotic spindle is fully formed, so the linked centromere has not made strong attachments to either spindle pole.

which TRKIN binds and pulls TR1 knobs toward spindle poles by directly walking on microtubules, just like the 180-bp/Kindr system.

Despite forming neocentromeres, the ability of the TR1 knobs to drive independently of the 180-bp/Kindr system is still unclear (Kanizay et al. 2013). For example, Kindr mutants abolish Ab10 drive, even in the presence of Ab10 TR1 neocentromeres (Dawe et al. 2018). The investigators hypothesize that TR1 neocentromeres primarily serve an ancillary role to increase the efficiency of 180 $\mathrm{bp} /$ Kindr drive. In support of this, the investigators found that knobs are usually composed of a mixture of both TR1 and 180-bp repeat arrays, consistent with the idea that the two repeats cooperate to increase drive.

The investigators propose that the TR1/Trkin system can resolve directional conflicts between knobs and their linked centromeres. Specifically, TR1/Trkin may help prevent chromosome breakage during anaphase I by preventing knobs and centromeres on the same chromosome from attaching to microtubules from opposite spindle poles (Fig. 1B). Considering that the investigators found that TRKIN moves more slowly along microtubules than KINDR in vitro, TRKIN may quickly dissociate from microtubules to help change directions on the spindle, whereas KINDR processively moves knobs toward spindle poles. As noted by the investigators, this model could be tested by comparing the rates of chromosome breakage in the natural Ab10 variants with and without TR1 neocentromere activity. TR1/Trkin might also help orient its linked centromere toward the terminal spindle pole during meiosis II (Fig. 1C). Because TRKIN can be imported into the nucleus, it can associate with TR1 knobs early during prophase II. As the spindle begins to form around chromatin upon nuclear envelope breakdown, TR1 neocentromeres might apply tension to their linked centromeres before they form stable kinetochore-micro- tubule interactions and help orient them toward the terminal spindle pole. This hypothesis can be tested by determining the effects of Trkin mutants missing the nuclear localization sequence.

Swentowsky et al. (2020) have shown that TR1 and 180bp repeat knobs recruit their own novel and divergent kinesin-14 family member to pull themselves toward spindle poles. The prevalence of mixed knobs suggests that both repeats play distinct but cooperative roles in meiotic drive. Future studies could determine how KINDR and TRKIN bind to their respective knob repeats: Do they directly interact with knob DNA or do they need adapter proteins? It would also be interesting to determine whether KINDR and TRKIN need to bind their specific DNA repeat in order to form neocentromeres and achieve meiotic drive, or whether another DNA sequence engineered to bind the motors would do the same.

\section{References}

Akera T, Trimm E, Lampson MA. 2019. Molecular strategies of meiotic cheating by selfish centromeres. Cell 178: 11321144.e10. doi:10.1016/j.cell.2019.07.001

Burt A, Trivers R. 2006. Genes in conflict: the biology of selfish genetic elements. Belknap Press of Harvard University Press, Cambridge, MA.

Dawe RK, Lowry EG, Gent JI, Stitzer MC, Swentowsky KW, Higgins DM, Ross-Ibarra J, Wallace JG, Kanizay LB, Alabady M, et al. 2018. A Kinesin-14 motor activates neocentromeres to promote meiotic drive in maize. Cell 173: 839-850.e18. doi:10.1016/j.cell.2018.03.009.

Kanizay LB, Albert PS, Birchler JA, Kelly Dawe R. 2013. Intragenomic conflict between the two major knob repeats of maize. Genetics 194: 81-89. doi:10.1534/genetics.112.148882

Kelly Dawe R, Reed LM, Yu HG, Muszynski MG, Hiatt EN. 1999. A maize homolog of mammalian CENPC is a constitutive 
component of the inner kinetochore. Plant Cell 11: 12271238. doi:10.1105/tpc.11.7.1227

Rhoades MM. 1942. Preferential segregation in maize. Genetics 27: 395-407.

Rhoades MM. 1952. Preferential segregation in maize. In Heterosis (ed. JW Gowen), pp. 66-80. Iowa State College Press, Ames, Iowa.
She Z, Yang W. 2017. Molecular mechanisms of kinesin-14 motors in spindle assembly and chromosome segregation. J Cell Sci 130: 2097-2110. doi: 10.1242/jcs.200261

Swentowsky KW, Gent JI, Lowry EG, Schubert V, Ran X, Tseng KF, Harkess AE, Qiu W, Dawe RK. 2020. Distinct kinesin motors drive two types of maize neocentromeres. Genes Dev (this issue). doi:10.1101/gad.340679.120 


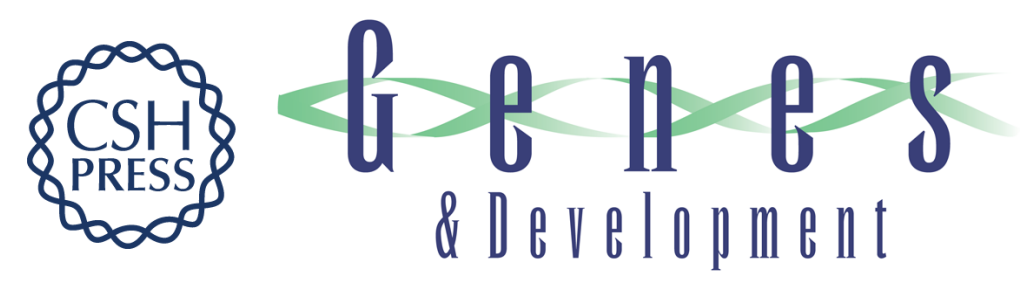

\section{Mixed knobs in corn cobs}

Piero Lamelza and Michael A. Lampson

Genes Dev. 2020, 34:

Access the most recent version at doi:10.1101/gad.343350.120

Related Content Distinct kinesin motors drive two types of maize neocentromeres

Kyle W. Swentowsky, Jonathan I. Gent, Elizabeth G. Lowry, et al.

Genes Dev. September , 2020 34: 1239-1251

References This article cites 7 articles, 5 of which can be accessed free at:

http://genesdev.cshlp.org/content/34/17-18/1110.full.html\#ref-list-1

Articles cited in:

http://genesdev.cshlp.org/content/34/17-18/1110.full.html\#related-urls

Creative This article is distributed exclusively by Cold Spring Harbor Laboratory Press for the first

Commons

License

six months after the full-issue publication date (see

http://genesdev.cshlp.org/site/misc/terms.xhtml). After six months, it is available under a Creative Commons License (Attribution-NonCommercial 4.0 International), as described at http://creativecommons.org/licenses/by-nc/4.0/.

Email Alerting Receive free email alerts when new articles cite this article - sign up in the box at the top Service right corner of the article or click here.

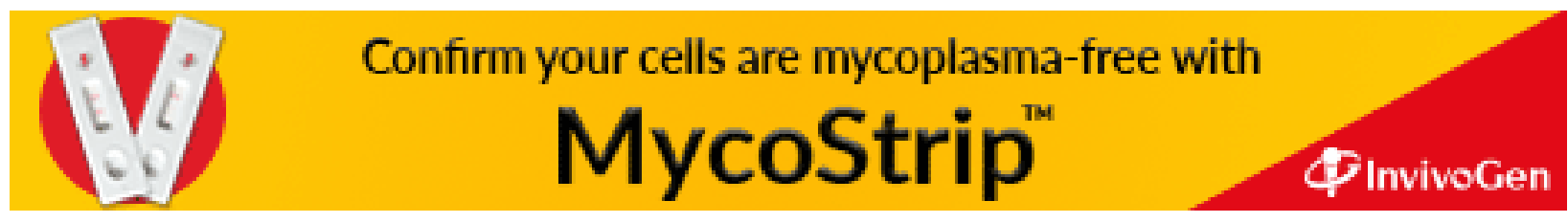

